\title{
Which patients are prescribed inhaled anti-asthma drugs?
}

\author{
S J Roberts, D N Bateman
}

\begin{abstract}
Background - Prescribing rates for inhaled anti-asthmatic drugs in the $U K$ vary considerably from area to area and between individual practices. The objectives of this study were to determine the prevalence of patients prescribed inhaled steroids and $\beta$ agonist bronchodilators, the indications for these prescriptions, and to relate prescribing to the recorded levels of morbidity for specific respiratory disease. Methods - Anonymised patient-specific prescription and diagnostic data were extracted from computerised general practice records for the 41 practices in the Northern region (total population 330 749) whose data had been validated for inclusion in a research databank. Patients were included if they were either prescribed an inhaled steroid or bronchodilator during a 12 month period, or had a recorded diagnosis of asthma, bronchitis or chronic obstructive pulmonary disease. Prescribing of inhalers per 1000 population was determined within age, sex, and diagnostic groups. Respiratory diagnosis rates within different patient groups were used to measure the underlying level of morbidity in the population.
\end{abstract}

Results - Inhaled anti-asthma drugs were prescribed for $5 \%$ of the study population. Prescribing prevalences peaked at ages 5-14 (steroids 40 per 1000 population; bronchodilators 68 per 1000) and at ages 65-74 (steroids 53 per 1000; bronchodilators 79 per 1000). Prescribing frequency for both drugs increased from two or three items per patient annually at age 0-14 to about six in the over 65 age group. Of the 39424 respiratory patients $38 \%$ received inhalers and $7 \%$ only non-inhaler medication. Inhaler therapy was used in only $6 \%$ of patients with bronchitis, but in $66 \%$ of those with asthma, though the proportions varied with patient age and gender. Study practices differed in their overall levels of both inhaler prescribing and respiratory diagnosis, and had lower prescribing patterns of these drugs than other practices in the Northern region.

Conclusions - Inhaled steroid and bronchodilator prescribing have age-related and gender-related prevalences. Treat- ment for respiratory diagnoses varies with patient age and gender, and with the diagnosis. Prescribing differences between practices are attributable to variation in both diagnostic rates for respiratory disease and therapeutic intervention patterns. For asthma patients study practices show consensus in approach, perhaps illustrating the value of clear guidelines for asthma prescribing.

(Thorax 1994;49:1090-1095)

Prescribing is a major element in the delivery of primary health care, and its considerable variability across the UK has been much discussed. $^{1-4}$ Variations exist at all levels: health regions, family health service authorities (FHSAs), practices, and individual prescribers. The reasons underlying these differences are unclear. Explanations of prescribing variation in terms of demographic, morbidity, and practice factors have been suggested but these have largely been regression models which "best explain" the observed variation at FHSA or practice level, using population based values. ${ }^{125}$ Studies linking prescriptions to individual patient characteristics are less common, ${ }^{46}$ and often relate to only a few practices. In order to explain variability we first need to know which patients actually receive the prescriptions and why.

Drugs used for a wide variety of indications have more potential sources of prescribing variation and are impractical for detailed pharmaco-epidemiological studies. However, inhaled corticosteroids and $\beta$ agonist bronchodilators have a well defined role in the treatment of specific respiratory disease, and guidelines for their use in asthmatic patients have been published by the British Thoracic Society. ${ }^{78}$ Nonetheless, usage of these preparations is subject to substantial variation when considered at practice or FHSA level. ${ }^{9}$ In this paper patientbased prescribing data have been used to examine the demographic profile of patients actually receiving inhaled anti-asthma drugs, the indications for their prescription, and the quantities prescribed per patient. In addition, the alternative treatments received by patients with a recorded diagnosis of asthma, bronchitis and chronic obstructive pulmonary disease (COPD) are examined. 


\section{Methods}

\section{DATA COLLECTION}

The patient-specific prescribing and morbidity data analysed were obtained from the 41 practices in the Northern Region who use a specific general practitioner computer system (the Vamp system) for their patient data, and who also have their data validated for inclusion in an anonymised databank held by Vamp Research Ltd. ${ }^{10}$ The computer system is used to issue prescriptions and record diagnoses, hospital referrals, and other patient details. For each practice the data covered a 12 month period, the majority of which ended in the first quarter of 1993 but in four practices related to earlier periods (ending in December 1992, October 1992, February 1992, and February 1991). To maintain patient and practice confidentiality the data were amalgamated into practice groups on a geographical basis. Seven of the eight groups were based on single FHSAs (Cleveland, Cumbria, Durham, Northumberland, Newcastle, South Tyneside, Sunderland), and the eighth consisted of one practice in North Tyneside and two practices in Gateshead. Overall the study population comprised 330749 individuals $(10.5 \%$ of the registered population of the Northern Regional Health Authority). The groups consisted of 3-8 practices, serving between $7 \%$ and $23.4 \%$ of the resident populations in the corresponding geographical areas (family health service authorities). Detailed population breakdown according to age and gender was available within each group of practices.

Patients were defined as those who, during the study period, were issued with one or more prescriptions for inhaled anti-asthma drugs, or for whom the database included a diagnosis record for asthma, bronchitis or COPD. For each patient issued a prescription for inhaled steroids (beclomethasone, budesonide) or bronchodilators (salbutamol, terbutaline, fenoterol, salmeterol), drug-based data detailed the number of prescriptions issued during the year, the daily dose of the first prescription, and all recorded indications for the prescription. For patients with a recorded diagnosis of asthma, bronchitis or COPD, the data included both the diagnosis and information on all respiratory medicines prescribed (if any). Both prescription indications and respiratory diagnoses were derived from OXMIS codes in the computerised patient record. OXMIS problem codes are a classification system specifically devised for use in primary care by the Oxford Community Health Project. ${ }^{11}$ The codes relevant to this study covered a wide variety of diagnostic terms categorised into three broad therapeutic indications: asthma (48 diagnostic terms), bronchitis (8 terms), and COPD (36 terms). The COPD category included some diagnostic phrases which were less precise (for example, breathing difficulty, lung function test abnormal), and as such could be compatible with asthma. The numbers were small and in the second part of the study these latter terms were excluded as diagnostic criteria for patients with specific respiratory disease.

For comparison, FHSA level data for inhaled steroids and bronchodilators were extracted from aggregated FHSA prescribing catalogues for the year ending 31 March 1993. The numbers of items were taken from the relevant subsections of the British National Formulary, Chapter 3 (respiratory drugs). In addition, data were obtained from FHSA registers on the overall numbers of patients in predetermined age and sex bands.

\section{ANALYSIS OF DATA}

Patients receiving inhaled anti-asthma drugs

The numbers of patients who received one or more prescriptions for inhaled steroids or bronchodilators during the study period were analysed according to the patient's age, gender, practice group (FHSA), drug group (steroid or bronchodilator), and indication for prescription. Those patients who received more than one drug from within a group (for example, two different bronchodilator preparations) were counted only once for this purpose. Age-specific and gender-specific prescribing rates were calculated as the number of patients in receipt of a prescription per 1000 registered population. These rates were calculated both overall and for the geographically defined practice groups.

Within each patient age and sex category the average number of bronchodilator prescriptions issued per patient per year was calculated, as was the corresponding annual number of steroid prescriptions.

The broad indications for inhaler prescriptions within each drug group were also analysed. Log-linear models were used to examine the effects of patient age, gender, prescription indication (asthma/no asthma), and practice group on patient prevalence rates.

\section{Patients with respiratory diagnoses}

All patients with a recorded diagnosis of the three principal indications for treatment with bronchodilator or steroid inhalers (asthma, bronchitis, COPD) were identified and diagnostic prevalence rates per 1000 population by age and gender were derived. The proportions of diagnosed patients receiving inhalers, other respiratory drugs, or no drug treatment during the study period were also calculated. Diagnostic prevalence and drug treatment rates were evaluated separately for each of the eight groups of practices to ascertain the variability in both recorded morbidity rates and therapeutic intervention for specific diagnoses.

\section{Comparisons between prescribing in study} practices and in the local populations

Prescribing rates are known to vary substantially with patient age and gender. ${ }^{6}$ To make valid comparisons between the prescribing observed in the study practices and the equivalent prescribing for the Northern region as a whole, or for individual FHSAs, demographic differences were accommodated by using age-specific rates obtained from the study practices. Indirect standardisation methods ${ }^{12}$ were used 
Table 1 Numbers (\%) of patients prescribed inhaled anti-asthma drugs, and alternative treatment for those with respiratory diagnoses in a study population of 330749 registered patients

\begin{tabular}{|c|c|c|c|c|c|}
\hline \multirow[t]{2}{*}{ Treatment } & \multirow{2}{*}{$\begin{array}{l}\text { Patients prescribed } \\
\text { inhaled anti- } \\
\text { asthma drugs }\end{array}$} & \multicolumn{4}{|c|}{ Patients with respiratory diagnoses } \\
\hline & & All diagnoses & Asthma & COPD (no asthma) & Bronchitis alone \\
\hline $\begin{array}{l}\text { Inhalers } \\
\text { Steroid } \\
\text { Bronchodilator } \\
\text { Steroid + bronchodilator } \\
\text { Combination preparations* } \\
\text { Other drugs** } \\
\text { No therapy } \\
\text { Total }\end{array}$ & $\begin{array}{c}16701(5 \cdot 0) \\
1090(0 \cdot 3) \\
7225(2 \cdot 2) \\
7895(2 \cdot 4) \\
491\end{array}$ & $\begin{array}{r}14888(4 \cdot 5) \\
911(0 \cdot 3) \\
5874(1 \cdot 8) \\
7705(2 \cdot 3) \\
398 \\
2662(0 \cdot 8) \\
21874(6 \cdot 6) \\
39424(11 \cdot 9)\end{array}$ & $\begin{array}{r}12229(3 \cdot 7) \\
792 \\
4373 \\
6776 \\
288 \\
1173 \\
5191 \\
18593(5 \cdot 6)\end{array}$ & $\begin{array}{l}1605(0 \cdot 5) \\
77 \\
751 \\
727 \\
50 \\
358 \\
1391 \\
3354(1 \cdot 0)\end{array}$ & $\begin{array}{l}1054(0 \cdot 3) \\
42 \\
750 \\
202 \\
60 \\
1131 \\
15292 \\
17477(5 \cdot 3)\end{array}$ \\
\hline
\end{tabular}

* Combination inhaler preparations: salbutamol/beclomethasone, fenoterol/ipratropium.

** Other respiratory drugs: oral $\beta$ agonist bronchodilators, sympathomimetic drugs (adrenaline, orciprenaline, ephedrine, isoprenaline), theophylline, cromoglycate, and ipratropium/oxitropium.

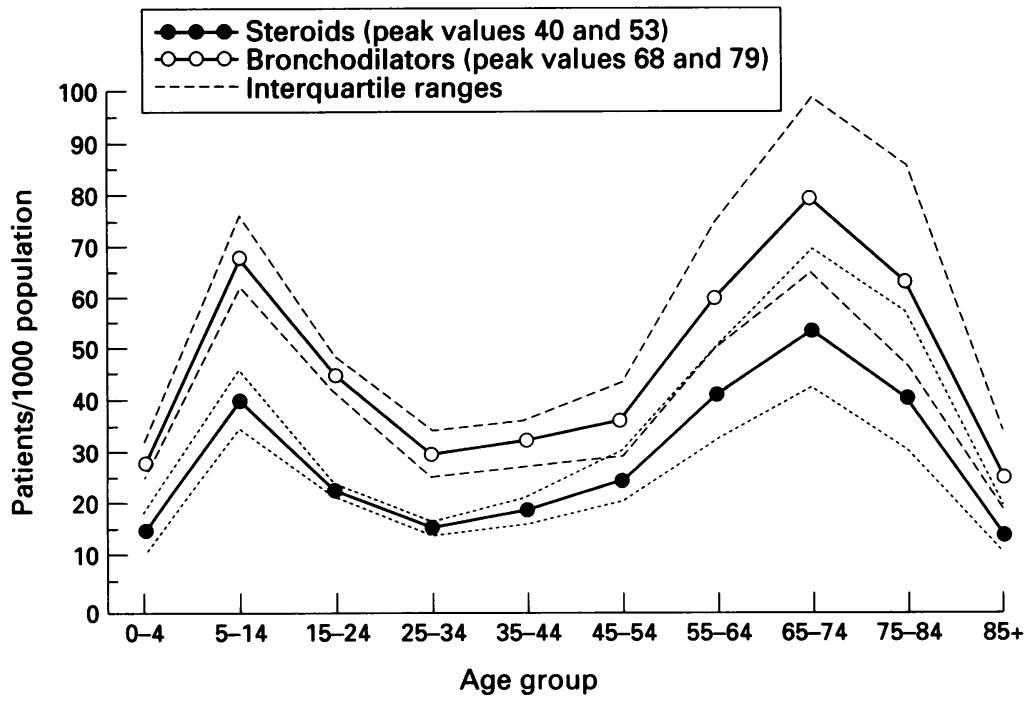

Figure 1 Prescribing prevalence of inhaled drugs. Overall rates for 41 study practices, together with quartiles of eight rates based on practices grouped geographically by $F H S A$.

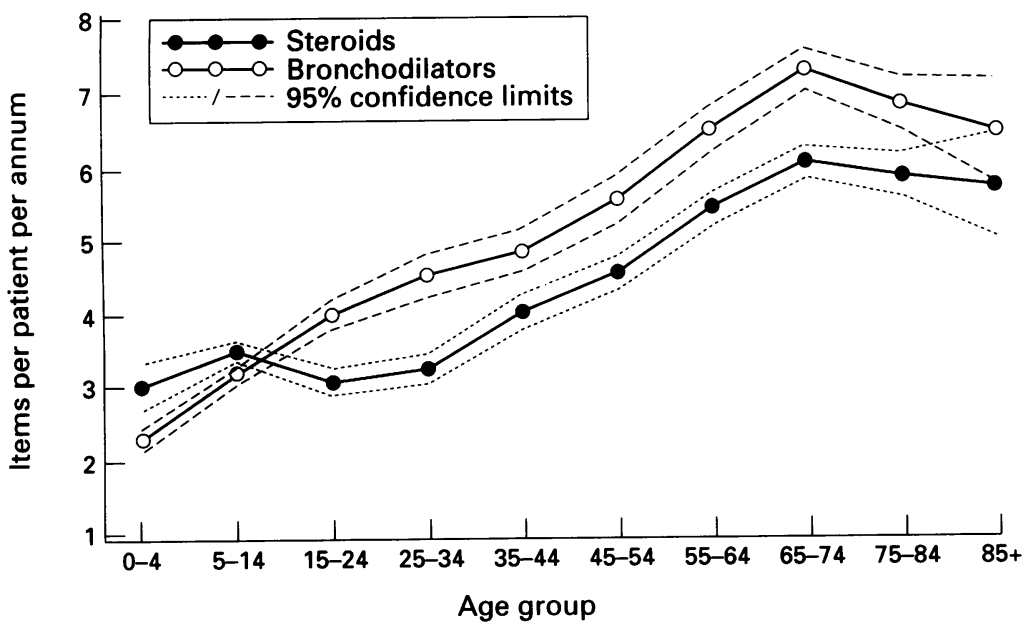

Figure 2 Average annual number of items per patient, according to patient age. to calculate the expected number of items for each drug group, both regionally and at FHSA level. Confidence limits for estimates were obtained by assuming that the number of patients in receipt of prescriptions for a drug was binomially distributed with the proportion dependent on patient age and sex. The mean and variance of the number of prescriptions per patient (conditional on receiving a prescription) were estimated by the sample values derived from the corresponding age and sex band of the study data.

\section{Results}

AGE-SPECIFIC AND SEX-SPECIFIC PRESCRIBING RATES

In the study period 16701 patients were prescribed inhaled anti-asthma drugs, the majority receiving bronchodilators, either alone or with steroids (table 1). Age-related patient prevalence rates for inhaled steroids and bronchodilators are shown in fig 1 and exclude the 491 patients who received only compound inhaled preparations. The magnitude of the peak at age 65-74 varied substantially between the eight practice groups, as indicated by the wider interquartile range. Relative prevalences of prescribing for men compared with women were similar for the two types of inhaled drugs (table 2).

Within each age band men and women were prescribed similar numbers of items annually, but this annual prescription frequency increased steadily with age (fig 2 ). Practice groups consistently showed the same age trends, though their absolute rates varied slightly. The frequency distribution of annual prescribing was multimodal with peaks at $1,6-7$, and 12-13 items, with a progressive shift from single prescriptions in younger patients to one-month or two-month repeat prescribing in the elderly

Table 2 Relative gender prevalence (with 95\% confidence limits) of patients prescribed inhaled anti-asthma drugs, and of patients with respiratory diagnoses. Ratios are males/females and based on all 41 practices

\begin{tabular}{|c|c|c|c|c|c|}
\hline \multirow{2}{*}{$\begin{array}{l}\text { Age } \\
\text { groups }\end{array}$} & \multicolumn{2}{|l|}{ Inhaled drug } & \multicolumn{3}{|l|}{ Respiratory diagnosis } \\
\hline & Bronchodilator & Steroid & All diagnoses & Asthma & COPD (no asthma) \\
\hline $\begin{array}{l}0-4 \\
5-14 \\
15-24 \\
25-34 \\
35-44 \\
45-54 \\
55-64 \\
65-74 \\
75-84 \\
85+\end{array}$ & $\begin{array}{l}1.48(1.30 \text { to } 1.67) \\
1.48(1.40 \text { to } 1.56) \\
1.04(0.98 \text { to } 1.11) \\
0.88(0.82 \text { to } 0.94) \\
0.71(0.66 \text { to } 0.76) \\
0.81(0.75 \text { to } 0.87) \\
0.96(0.90 \text { to } 1.03) \\
1.21(1.15 \text { to } 1.28) \\
1.44(1.33 \text { to } 1.56) \\
1.48(1.23 \text { to } 1.78)\end{array}$ & $\begin{array}{l}1.66(1.39 \text { to } 1.98) \\
1.54(1.43 \text { to } 1.66) \\
0.88(0.81 \text { to } 0.96) \\
0.89(0.81 \text { to } 0.98) \\
0.64(0.57 \text { to } 0.70) \\
0.83(0.75 \text { to } 0.91) \\
0.98(0.90 \text { to } 1.06) \\
1.21(1.13 \text { to } 1.30 \\
1.36(1.23 \text { to } 1.50) \\
1.60(1.24 \text { to } 2.06)\end{array}$ & $\begin{array}{l}1.30(1.24 \text { to } 1.36) \\
1.37(1.32 \text { to } 1.42) \\
1.13(1.08 \text { to } 1.17) \\
0.87(0.84 \text { to } 0.91) \\
0.77(0.74 \text { to } 0.80) \\
0.78(0.75 \text { to } 0.82) \\
0.85(0.82 \text { to } 0.89) \\
1.04(1.00 \text { to } 1.07) \\
1.13(1.08 \text { to } 1.18) \\
1.13(1.03 \text { to } 1.25)\end{array}$ & $\begin{array}{l}1.43(1.33 \text { to } 1.54) \\
1.47(1.41 \text { to } 1.53) \\
1.22(1.16 \text { to } 1.28) \\
1.04(0.98 \text { to } 1.10) \\
0.79(0.74 \text { to } 0.84) \\
0.85(0.79 \text { to } 0.91) \\
0.87(0.81 \text { to } 0.93) \\
1.02(0.95 \text { to } 1.09) \\
1.07(0.97 \text { to } 1.17) \\
1.15(0.91 \text { to } 1.44)\end{array}$ & $\begin{array}{l}0.62(0.42 \text { to } 0.92) \\
0.73(0.48 \text { to } 1.11) \\
0.94(0.59 \text { to } 1.50) \\
0.52(0.32 \text { to } 0.83) \\
0.82(0.62 \text { to } 1.09) \\
1.13(0.94 \text { to } 1.35) \\
1.28(1.15 \text { to } 1.43) \\
1.45(1.34 \text { to } 1.57) \\
1.77(1.61 \text { to } 1.96) \\
1.57(1.28 \text { to } 1.93)\end{array}$ \\
\hline
\end{tabular}



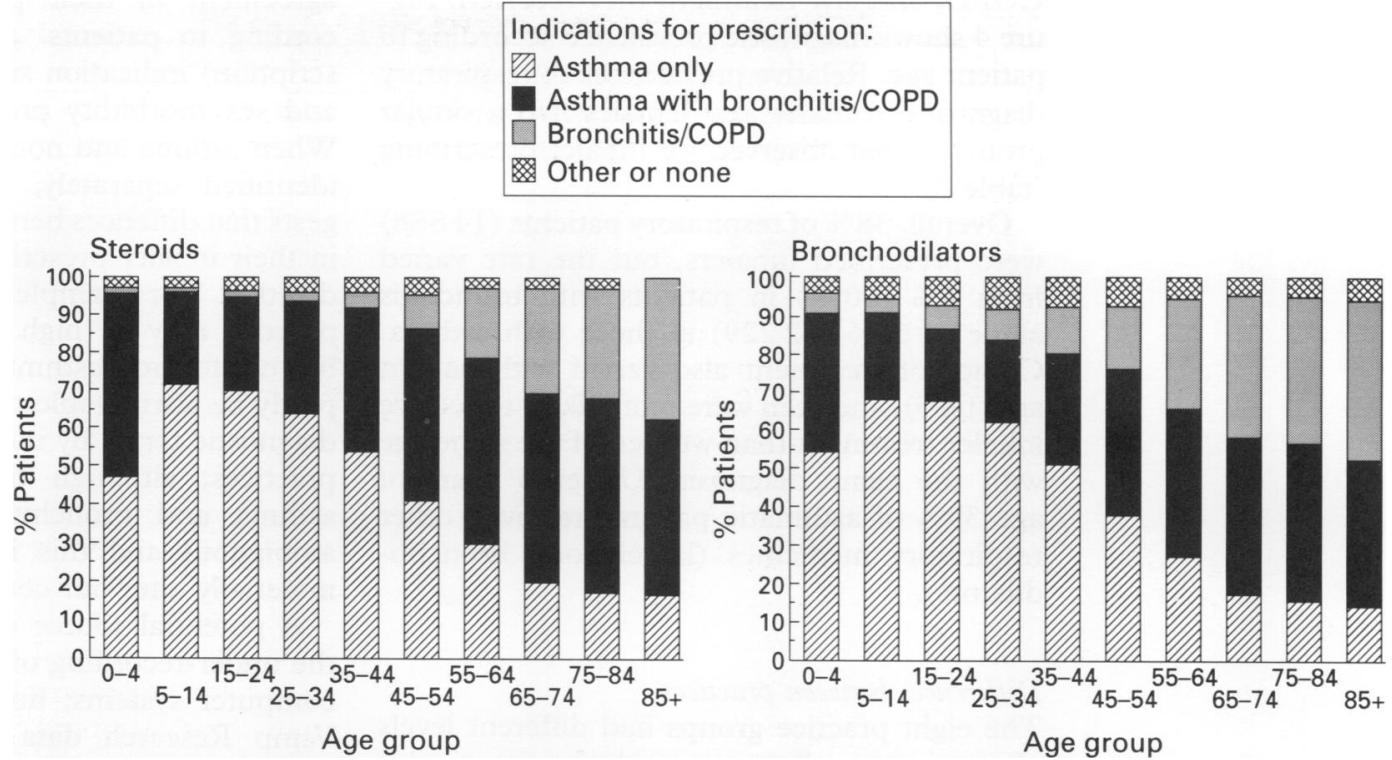

Figure 3 Indications for prescriptions of inhaled anti-asthma drugs, according to patient age.

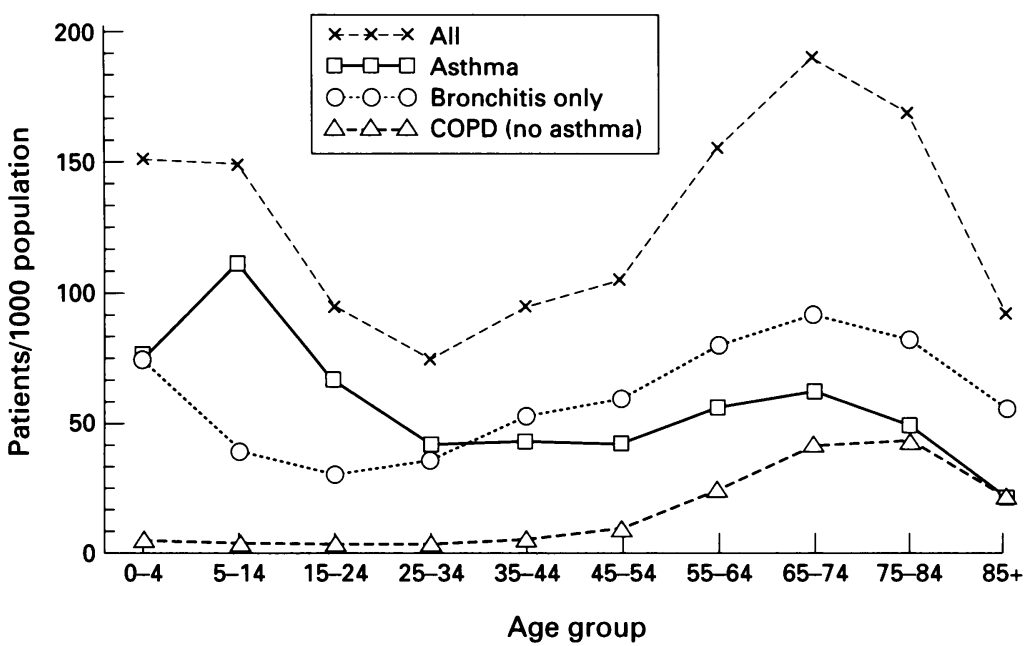

Figure 4 Prevalence of study patients with different respiratory diagnoses.

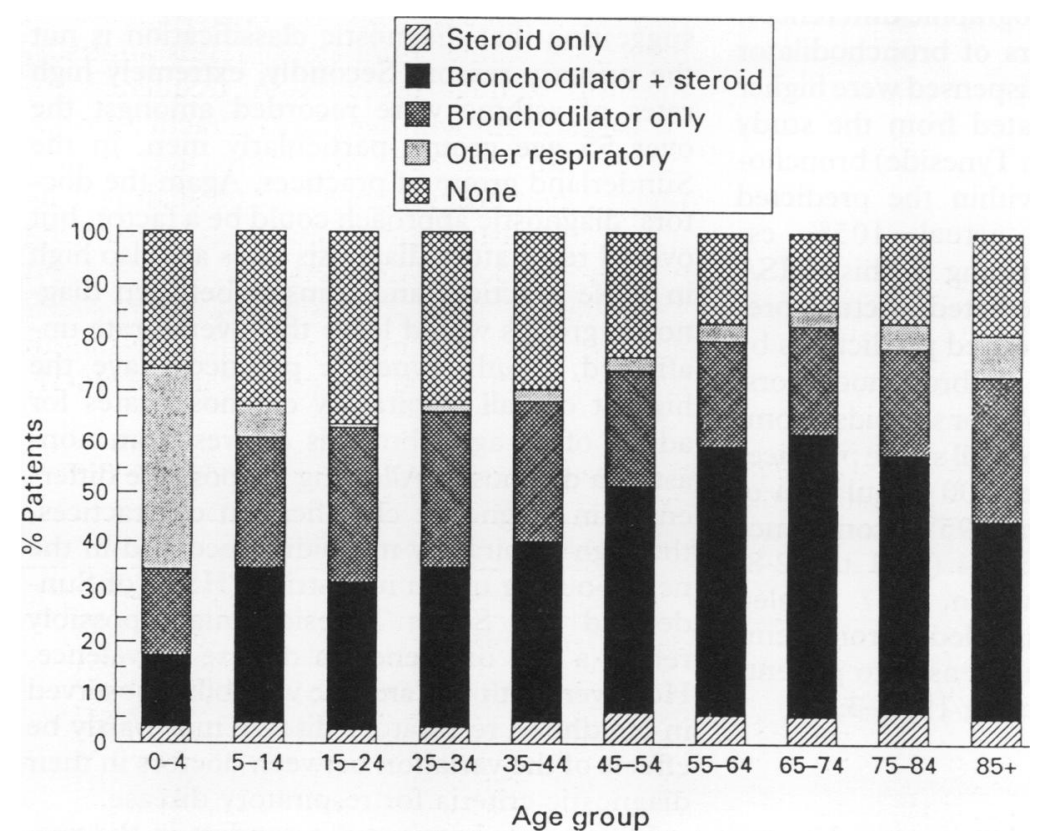

Figure 5 Drugs prescribed for all study patients with an asthma diagnosis.
- for example, for steroids $39 \%$ of patients aged 15-24 had single items but only $12 \%$ aged 65-74 years.

\section{Indications for prescription}

Overall, $85 \%$ of patients receiving steroids and $76 \%$ of those given bronchodilators had prescription indications which included asthma. Amongst the under 15 age group asthma accounted for over $90 \%$ of indications for both drug groups (fig 3), but this proportion decreased with age. Thus asthma was not the given indication in $47 \%$ of men and $37 \%$ of women aged 65 or over who were prescribed bronchodilators. Similar gender differences applied to steroids. Prescribing prevalence for asthma indications retained the bimodal age profile observed for overall steroid and bronchodilator prescribing, but for non-asthma indications the rates were low until age 55 and then peaked at $65-74$ years (steroids 16 per 1000; bronchodilators 33 per 1000).

In log-linear models for both steroid and bronchodilator prescribing prevalen $u$, the effects of patient age, gender, prescription indication (asthma/no asthma), and practice group were all significant, as were the interactions between age, gender, and prescription indication, and the interaction between practice group and prescription indication. Thus, within an indication, the practice groups all had consistent profiles across the age and sex bands, although their absolute rates were different. These differences between practices were not consistent for the indications "asthma" and "no asthma". Two practice groups (Sunderland and South Tyneside) had particularly high rates for non-asthma indications where prescribing is largely for older patients.

\section{Respiratory diagnoses and therapy}

Table 1 shows the number of patients with recorded diagnoses of asthma, bronchitis, or 
COPD, and any treatment they received. Figure 4 shows diagnostic prevalence according to patient age. Relative prevalences of respiratory diagnoses in males and females had a similar profile to that observed for inhaler prescribing (table 2).

Overall, $38 \%$ of respiratory patients ( 14888 ) were prescribed inhalers, but the rate varied from $6 \%(1054)$ in patients with bronchitis alone to $66 \%$ (12229) in those with asthma. Choice of treatment also varied with patient age (fig 5), and men were more likely to receive inhaler treatment than women of the same age with the same diagnosis. Under 5 years of age $39 \%$ of asthmatic patients received other respiratory medicines (largely oral bronchodilators).

\section{Differences between practices}

The eight practice groups had different levels of respiratory diagnosis and therapeutic intervention rates. In all age bands the South Tyneside group had high rates for non-asthma diagnoses and in the over 45 age groups rates were $50 \%$ higher than for any other practice group. Their asthma diagnosis rates were close to average. The Sunderland group had very high rates of asthma diagnosis in the over 55 age groups, and above average rates for nonasthma. Overall prevalence of respiratory diagnoses in children under 15 years ranged from 110 per 1000 population (Cumbria practices) to 220 per 1000 (Northumberland). For asthma diagnoses rates ranged from 44 to 113 per 1000 population aged $0-4$ years, and from 84 to 150 per 1000 at ages 5-14.

\section{Comparisons between prescribing in study \\ practices and in the local populations}

Study practices had a small excess both of elderly and of female patients compared with the registered population of the Northern region. Statistical comparisons between prescribing in local and study populations accommodated these demographic differences. In all FHSAs the numbers of bronchodilator and steroid prescriptions dispensed were higher than the estimates calculated from the study data. In one locality (South Tyneside) bronchodilator prescribing was within the predicted $95 \%$ confidence limits (actual $=105 \%$ estimate), but steroid prescribing in this FHSA was $13 \%$ higher than predicted. Actual prescribing in other areas exceeded predictions by between $19 \%$ and $117 \%$ for bronchodilators, and between $36 \%$ and $116 \%$ for steroids. Combined age-specific rates from all study practices gave regional estimates per 100 population of 23.7 bronchodilator items (95\% confidence limits $23 \cdot 1$ to $24 \cdot 3)$, and $12 \cdot 4(12 \cdot 1$ to $12 \cdot 8)$ steroid items. By comparison, $32 \cdot 7$ inhaled bronchodilator and $18 \cdot 1$ inhaled steroid items per 100 population were dispensed to patients in the Northern region during 1992-3.

\section{Discussion}

Although there is variation between study practices in their absolute levels of prescribing, the agreement in their prescribing profiles according to patients' age, gender, and (prescription) indication suggests a consistent age and sex morbidity profile in the population. When asthma and non-asthma indications are identified separately, statistical analysis suggests that diffences between groups of practices in their inhaler prescribing depend on the indication. For example, prescribing levels in a practice may be high for asthma indications but not for non-asthma ones. Differences may partly be attributable to the variation in use of diagnostic terms by individual practitioners or practices, although the OXMIS codes for asthma and bronchitis are reasonably unambiguous and this is therefore unlikely to materially alter our conclusions.

A potential source of error in this study is the under-recording of prescribing on practice computer systems; however, practices in the Vamp Research data bank are reported to achieve $95 \%$ recording rates for prescriptions. ${ }^{10}$ Against this must be set the numbers of prescriptions issued to patients though never dispensed, which a recent study ${ }^{13}$ of primary noncompliance reported at $5 \cdot 1 \%$ overall, and $4.6 \%$ for respiratory drugs. In practice these two effects are likely to cancel each other out.

Reasons for the variation in prescribing levels between practice groups are more readily identified by considering all patients with a relevant respiratory diagnosis, thereby allowing comparison of both perceived morbidity levels and therapeutic intervention rates. Diagnostic rates for asthma, including asthma concurrent with other respiratory disease, show two main differences between practice groups. Firstly, there is a twofold variation in children under 15 years. The observed rates $(8-15 \%$ in those aged 5-14) are not dissimilar to those found in other studies, ${ }^{14-16}$ but it seems unlikely that true asthma morbidity rates are this wide ranging locally. Imprecise differentiation between (acute) bronchitis and asthma could be a contributory factor, although overall respiratory diagnosis rates in children vary almost as much, suggesting that diagnostic classification is not the primary reason. Secondly, extremely high rates of asthma were recorded amongst the over 55 age group, particularly men, in the Sunderland group of practices. Again the doctors' diagnostic approach could be a factor, but overall respiratory diagnosis rates are also high in these practices and transfer between diagnostic groups would leave this overall rate unaffected. South Tyneside practices have the highest overall respiratory diagnosis rates for adults of all ages, but this derives from nonasthma diagnoses. Allowing for possible differences in diagnostic classification of practices, the high respiratory morbidity recorded in the neighbouring urban industrial FHSAs of Sunderland and South Tyneside might possibly reflect a real difference in disease prevalence. However, both this and the variability observed in childhood respiratory disease may partly be effects of the variation between doctors in their diagnostic criteria for respiratory disease.

Differences between the genders in the prevalence of inhaler use are largely a reflection of 
differing diagnostic rates for respiratory disease rather than in the choice of treatment for diagnosed patients. Excess male respiratory morbidity in the elderly could be a consequence of the higher lifelong exposure of men to occupational air pollutants and smoking in this age group, particularly in the urban conurbations in the locality. The higher female disease prevalence in those aged 25-65 and the higher male rates in childhood have been observed by others, ${ }^{14}$ but the reasons are unclear. Gender differences in consultation patterns may play some part in the $25-65$ age group.

In the study population asthma is more prevalent in children aged 5-14 than in those aged 0-4 years, but the differences in inhaler prescribing are much more marked since most of the younger age group receive non-inhaler therapy. Treatment rates for asthma also show some variation between other age groups. Consequently crude prescribing rates cannot be used as a direct measure of asthma morbidity.

Inhaler use for asthma-diagnosed patients has a highly consistent age-related profile, with little variation between practice groups. This is likely to be influenced by the clear BTS guidelines $^{78}$ for the treatment of asthma patients. For other respiratory diagnoses there is substantial variation, with one group of practices having inhaler prescribing rates nearly three times higher than overall amongst adults with a sole diagnosis of bronchitis. Non-asthmatic patients comprise over $50 \%$ of the respiratory patients identified, so despite inhaler prescribing rates for these patients being substantially lower than for asthmatic subjects, this component has a considerable impact on overall inhaler prescribing and accounts for much of the variation, particularly over the age of 35 years.

There was a strong consensus between practice groups concerning the average annual number of prescriptions patients received. The gradual increase from two or three items per year in children to an average of about six in adults aged $65-85$ resulted from a decreasing number of patients receiving only one or two items, and an increasing number receiving 6-7 or 12-13 items. This shows a clear shift from the acute prescribing pattern to the chronic pattern with repeat prescriptions at one and two month intervals. The management of asthma appears to be age-dependent, with children receiving inhaler therapy principally for exacerbations.

Finally, despite considerable differences in the overall prescribing rates found in the groups of study practices, the rates are each lower than the corresponding FHSA rate for items dispensed to all patients. It is highly unlikely that this is due to fundamentally lower levels of morbidity in the study practices. Observed discrepancies almost certainly represent practice/practitioner influences, especially as the criteria for inclusion in the study were, by their very nature, selective of computerised general practices with documented high standards of data entry.

We gratefully acknowledge financial support from the Northern Regional Health Authority Research Directorate, and thank Vamp Research Ltd for the provision of data.

1 Forster DP, Frost CEB. Use of regression analysis to explain the variation in prescribing rates and costs between family practitioner committees. $\mathcal{F}$ Gen Pract 1991;41:67-71.

2 Morton-Jones AJ, Pringle MAL. Explaining variations in prescribing costs across England. $B M F$ 1993;306:1731-4.

$3 \mathrm{McG}$ avock $\mathrm{H}$. Some patterns of prescribing by urban general practitioners. BMF 1988;296:900-2.

4 Edwards C, Metcalfe D, Burr A, Watson K, Seward FCN, Jepson $\mathrm{MH}$, et al. Influence of patient age on drug costs: an investigation to validate the prescribing unit. Int $\mathcal{f}$ an investigation to validate

5 Purves IN, Edwards C. Comparison of prescribing unit with index including both age and sex in assessing general practice prescribing costs. BMF 1993;306:496-8.

6 Roberts SJ, Harris CM. Age, sex and temporary resident originated prescribing units (ASTRO-PUs): new weightings for analysing prescribing of general practices in England. $B M \mathcal{F} 1993 ; 307: 485-8$.

7 British Thoracic Society. Guidelines for management of asthma in adults: I - Chronic persistent asthma. BMf 1990;301:651-4.

8 British Thoracic Society. Guidelines for management of asthma in adults: II - Acute severe asthma. BMF 1990; 301:797-800.

9 Campbell M, Bateman DN, Smith JM. Analysis of GP prescribing in the Northern region using PACT data. $B$ f Clin Pharmacol 1992;34:184P.

10 Jick H, Jick SS, Derby LE. Validation of information recorded on general practitioner based computerised data resource in the United Kingdom. $B M \mathcal{F} 1991 ; 302: 766-8$.

11 Oxford Community Health Project. OXMIS problem codes for primary care. Oxford: OXMIS Publications, 1978.

12 Armitage P, Berry G. Statistical methods in medical research. 2nd edition. Oxford: Blackwell Scientific Publications, 1987:403.

13 Beardon PHG, McGilchrist MM, McKendrick AD, McDevitt DG, MacDonald TM. Primary non-compliance with vitt DG, MacDonald TM. Primary non-compliance with
prescribed medication in primary care. $B M \mathcal{F} 1993 ; 307$ : prescribed

14 Gellert AR, Gellert SL, Iliffe SR. Prevalence and management of asthma in a London inner city general practice. Br F Gen Pract 1990;40:197-201.

15 Hill R, Williams J, Britton J, Tattersfield AE. Can morbidity associated with untreated asthma in primary school children be reduced? A controlled intervention study. $B M \mathcal{F}$ 1991;303:1169-74.

16 Kolnaar BGM, van Lier A, van den Bosch WJHM, Folgering $\mathrm{H}$, van Herwaarden $\mathrm{C}$, van den Hoogen $\mathrm{HJM}$, et al. Asthma in adolescents and young adults: relationship with early childhood respiratory morbidity. Br f Gen Pract 1994; 44:73-8. 